\title{
ANALISIS KINERJA DOSEN TETAP PADA SEKOLAH TINGGI ILMU EKONOMI (STIE) DI PROVINSI LAMPUNG
}

\author{
Yunada $\operatorname{Arpan}^{1 *}$, Suwandi ${ }^{2}$ \\ 1. Sekolah Tinggi Ilmu Ekonomi Gentiaras, Lampung \\ 2. Institut Informatika dan Bisnis Darmajaya, Lampung \\ *email: yunada88@gmail.com
}

\begin{tabular}{|c|c|}
\hline$A R T I C L E$ & $A B S T R A C T$ \\
\hline Published: August 19, 2020 & \multirow{2}{*}{$\begin{array}{l}\text { The quality of human resources in a country is largely determined by the education } \\
\text { held in that country. As a higher education organization, it requires } \\
\text { organizational development to be able to provide quality educational services to } \\
\text { the community. To become a successful organization, the challenge for STIE in the } \\
\text { future is how to improve and apply the principles of professionalism for lecturers } \\
\text { as stated in Law Number } 14 \text { of } 2005 \text { concerning Teachers and Lecturers. This type } \\
\text { of research is causality (causality), which examines the cause-and-effect } \\
\text { correlation between the causal variables (exogent variables), namely } \\
\text { organizational development, transformational leadership and organizational } \\
\text { culture, to the consequent variables (endogent variables) consisting of commitment } \\
\text { and lecturer performance. The total population of all permanent lecturers and } \\
\text { structural officials who have had an Academic Position (JA) in } 7 \text { (seven) private } \\
\text { college (PTS) of Economics (STIE) in Lampung Province using non-probabilty } \\
\text { sampling technique is determined to be } 70 \text { lecturers. Based on the hypothesis } \\
\text { testing and discussion of the research results, it is obtained that the sub-structure } \\
\text { model equation1 is } \hat{\mathrm{Y}}=0,243 \mathrm{X}_{1}+0,200 \mathrm{X}_{2}+0,332 \mathrm{X}_{3}+\in_{1} . \text { Then the equation } \\
\text { for the Sub-structure model } 2 \text { is } \mathrm{Z}=0,170 \mathrm{X}_{1}+0,165 \mathrm{X}_{2}+0,260 \mathrm{X}_{3}+\in_{2} \text {. }\end{array}$} \\
\hline $\begin{array}{l}\text { Organizational development, } \\
\text { Transformational leadership, } \\
\text { Organizational culture, } \\
\text { Commitment and performance }\end{array}$ & \\
\hline I N F O A R T I K E L & \multirow{3}{*}{$\begin{array}{l}\text { A B S T R A K } \\
\text { Kualitas sumber daya manusia pada suatu negara sangat ditentukan oleh } \\
\text { pendidikan yang diselenggarakan di negara tersebut. Sebagai organisasi Perguruan } \\
\text { Tinggi memerlukan pengembangan organisasi agar mampu memberikan pelayanan } \\
\text { pendidikan yang berkualitas kepada masyarakat. Untuk menjadi sebuah organisasi } \\
\text { yang sukses, tantangan STIE ke depan adalah bagaimana meningkatkan dan } \\
\text { menerapkan prinsip-prinsip profesionalitas dosen seperti yang tertuang dalam } \\
\text { Undang-Undang Nomor } 14 \text { Tahun } 2005 \text { tentang Guru dan Dosen. Jenis penelitian } \\
\text { ini adalah causalitas (kausalitas) yaitu menguji hubungan sebab-akibat antara } \\
\text { variabel-variabel sebab (exogent variables) yakni pengembangan organisasi, } \\
\text { kepemimpinan transformasional dan budaya organisasi, terhadap variabel akibat } \\
\text { (endogent variabel) terdiri dari komitmen dan kinerja dosen. Jumlah populasi } \\
\text { seluruh dosen tetap dan pejabat struktural yang telah memiliki Jenjang Jabatan } \\
\text { Akademik (JA) di } 7 \text { (tujuh) PTS Sekolah Tinggi Ilmu Ekonomi }(\mathrm{STIE}) \text { di Provinsi } \\
\text { Lampung dengan dengan teknik non probabilty sampling ditentukan sebanyak } 70 \\
\text { orang dosen. Berdasarkan pengujian hipotesis dan pembahasan hasil penelitian } \\
\text { diperoleh persamaan model sub struktur1 adalah } \hat{Y}=0,249 \mathrm{X}_{1}+0,308 \mathrm{X}_{2}+0,237 \\
\mathrm{X}_{3}+\in_{1} \text { Kemudian persamaan model Sub Struktur } 2 \text { adalah } Z=Z ̌ Z=0,199 \mathrm{X}_{1}+ \\
0,260 \mathrm{X}_{2}+0,425 \mathrm{X}_{3}+\in_{2} \text {. }\end{array}$} \\
\hline Riwayat Artikel: & \\
\hline $\begin{array}{l}\text { Pengembangan organisasi, } \\
\text { Kepemimpinan transformasional, } \\
\text { Budaya organisasi, Komitmen } \\
\text { dan kinerja }\end{array}$ & \\
\hline
\end{tabular}




\section{PENDAHULUAN}

Dalam kurun waktu sepuluh tahun terakhir ini, terdapat beberapa peraturan yang mempunyai peranan penting dalam mengubah peta dunia pendidikan di Indonesia, di antaranya Undang-Undang Nomor 14 Tahun 2005 tentang Guru dan Dosen, dan Peraturan Pemerintah Nomor 19 Tahun 2005 tentang Standar Nasional Pendidikan. Dengan terbitnya Undang-Undang tersebut diharapkan berbagai masalah terkait dengan profesionalitas guru dapat diatasi. Profesionalitas guru akan terwujud melalui kualifikasi, sertifikasi, dan peningkatan kesejahteraan.

Seiring dengan era-globalisasi, terjadi perubahan pada lingkungan pendidikan. Perubahan ini relatif cepat dibandingkan dengan kemampuan lembaga pendidikan dalam meresponnya. Dalam rangka antisipasi situasi di atas, Perguruan Tinggi telah mengembangkan prinsip aktualisasi otonomi yang cocok, sederhana, produktif, dan adaptif. Pendidikan Tinggi berfungsi untuk mengembangkan kemampuan serta meningkatkan mutu kehidupan dan martabat manusia dalam rangka mewujudkan tujuan nasional, karena itu peningkatan kualitas sumber daya manusia merupakan syarat mutlak untuk menghadapi tantangan di masa datang. Kualitas sumber daya manusia pada suatu negara sangat ditentukan oleh pendidikan yang diselenggarakan di negara tersebut. Di Indonesia penyelenggaraan pendidikan di semua bidang sudah dilakukan, termasuk pendidikan tinggi, namun dampaknya pada perubahan kemajuan di Indonesia relatif masih kurang berarti.

Berdasarkan kondisi tersebut, saat ini beberapa Perguruan Tinggi Swasta khusus bidang ekonomi di Provinsi Lampung berusaha merespon kebutuhan negara tersebut melalui peningkatan kinerja para dosennya dengan cara memberikan kesempatan pada pegawai untuk tumbuh dan berkembang.

Sebagai organisasi, Perguruan Tinggi memerlukan pengembangan organisasi agar mampu memberikan pelayanan pendidikan yang berkualitas kepada masyarakat. Dalam Nawawi (2006), Fred Luthan mengatakan pengembangan organisasi, adalah pendekatan modern dalam manajemen terhadap perubahan dan perkembangan organisasi dari sudut SDM. French, Bell, Zawacki, (2000) mengatakan bahwa Pengembangan Organisasi (PO), merupakan respon terhadap perubahan yang berhubungan dengan segi pendidikan yang kompleks untuk merubah keyakinan, sikap, nilai-nilai dan struktur organisasi, agar mampu mengadaptasi secara baik teknologi baru, perubahan masyarakat yang dilayani, dan tantangan-tantangan di dalam perubahan yang rumit tersebut. Werther, William B, and Davis (1996), mengatakan bahwa PO adalah usaha jangka panjang untuk meningkatkan kemampuan sebuah organisasi dalam memecahkan masalah, dan proses pembaharuan, terutama melalui manajemen dan kerja sama yang lebih efektif sebagai budaya yang dikembangkan dalam organisasi. Pengertian ini menekankan pada pentingnya peran manajemen 
dan/atau kepemimpinan dalam memecahkan masalah organisasi dan melaksanakan proses pembaharuan, yang dilaksanakannya melalui kegiatan kerja sama yang berkelanjutan dan memiliki komitmen.

Pengertian komitmen merujuk pada kesetiaan dan loyalitas. Komitmen didefinisikan sebagai kekuatan relatif dari identifikasi dan keterlibatan individu kepada organisasi tertentu (Armstrong, 1995). Kiesler dan Sakumura seperti yang dikutip oleh Salancik mengartikan komitmen sebagai ikatan antara individu dan tindakan perilaku. Salancik (1995) bahkan menjelaskan bahwa kata komitmen diartikan sebagai suatu karakteristik intelektual, sifat pribadi seperti kejujuran, yang tidak dapat dimandatkan atau dipaksakan dari luar.

Dessler dalam Salancik (1995) mengatakan bahwa penciptaan komitmen membutuhkan suatu program yang komprehensif sehingga dia mempertanyakan harus mulai dari mana. Dessler (2004) namun seperti yang dikritisi oleh Armstrong bahwa dalam konsep komitmen terdapat tiga masalah utama, yaitu: (1) adanya penyederhanaan dalam menerima konsep komitmen sebagai suatu kerangka pikir yang sama (unitary frame of reference) dan ini merupakan asumsi yang tidak realistis karena suatu organisasi terdiri dari berbagai kepentingan manusia; (2) komitmen sebagai penghambat fleksibelitas, karena karyawan terikat dengan seperangkat nilai dan tujuan sehingga mereka tidak mampu mengatasi kebingungan dan ketidakpastian yang terjadi dalam kehidupan organisasi.

Akibatnya, kecocokan karyawan dengan nilai yang dipaksakan akan menghambat pemecahan masalah yang bersifat kreatif, resistensi terhadap perubahan dan tingkat stres tinggi, (3) terdapat suatu keyakinan nilai positif dari komitmen bahwa karyawan yang mempunyai komitmen tinggi berhubungan dengan tingkat perpindahan dan absensi karyawan yang rendah (Amstrong, 1995).

Pengembangan organisasi ini melihat komitmen karyawan atau organasasi dengan mengikuti proses merancang perubahan budaya organisasi dengan mempergunakan ilmu tentang perilaku teknologi (behavior science of technology), penelitian dan teori-teori yang relevan (Mullins, Laurie, 2010).

Menurut Jones dalam Wirawan (2007), budaya organisasi sebagai "...the set of shared values that control organizational members' interaction with each other and with suppliers, customers, and other people outside the organization."Artinya;...merupakan seperangkat nilai bersama yang mengontrol interaksi setiap anggota organisasi, juga dengan para pemasok, pelanggan, dan pihak-pihak lain di luar organisasi.” Sedangkan menurut Robert (2005) dalam mendefinisikan budaya organisasi sebagai: “...the norm that informs people what is acceptable and what is not, the dominant values that the organization cherishes above others, the basic assumption 
and beliefs that are shared by members of the organization, the 'rules' of the game that must be observed if one is to get along and be accepted as a member, the philoshophy that guide the organization in dealing with its employees and its clients".

Menurut Robins (2008) proses terciptanya budaya dalam organisasi banyak faktor yang menentukannya. Seperti yang disebutkan Robbins faktor-faktor yang mempengaruhi budaya organisasi adalah Inisiatif individu (individual initiative); Toleransi risiko (risk tolerance); Integrasi (integration); Dukungan manajemen (management support); Pengawasan (control); Identifikasi (identify); Sistem penghargaan (reward system); Toleransi terhadap konflik (conflict tolerance); Pola komunikasi (communication patterns). Menurut Keyton terdapat 5 karakteristik budaya organisasi "There are five core characteristics of organizational culture. Organizational culture is (a) inextricably linked to organizational members, (b) dynamic, not static, $(c)$ comprised of competing assumptions and values, (d) emotionally charged, and (e) both foreground and background for an organization's communication."

Menurut Wibowo (2006) ciri-ciri pengembangan organisasi yang efektif adalah Pengembangan organisasi merupakan suatu strategi terencana dalam mewujudkan perubahan organisasional. Program pengembangan organisasi menekankan cara-cara baru yang diperlukan guna meningkatkan kinerja seluruh anggota organisasi dan semua satuan kerja dalam organisasi terlepas dari tipe dan struktur organisasi yang diberlakukan, dan digunakan. Pengembangan organisasi mengandung nilai-nilai humanistik dalam arti bahwa dalam meningkatkan efektivitas organisasi, pengembangan potensi manusia harus menjadi bagian yang penting. Pengembangan organisasi menggunakan pendekatan kesisteman yang berarti selalu memperhitungkan pentingnya interelasi, interaksi dan interdependensi antara berbagai satuan kerja sebagai bagian integral dari suatu sistem.

Menurut Moeheriono (2012), pengertian kinerja sebenarnya berasal dari kata job performance dan disebut juga actual performance atau prestasi kerja atau prestasi sesungguhnya yang telah dicapai oleh seseorang karyawan.Sedangkan pengukuran kinerja (performance measurement) mempunyai pengertian suatu proses penilaian tentang kemajuan pekerjaan terhadap tujuan dan sasaran dalam pengelolaan sumberdaya manusia untuk menghasilkan barang dan jasa termasuk informasi atas efisiensi serta afektivitas tindakan dalam mencapai tujuan organisasi.

Menurut Robins (2008) kinerja sebagai fungsi interaksi antara kemampuan atau ability (A) motivasi atau motivation $(\mathbf{M})$ dan kesempatan atau opportunity $(\mathbf{O})$, yaitu kinerja $=\mathbf{f}(\mathbf{A x M x O})$, artinya kinerja merupakan fungsi dari kemampuan, motivasi, kesempatan. Sedangkan kinerja menurut The Scriber-Bantam English Dictionary berasal dari kata... "to perfom" dengan beberapa entries yaitu: (1) melakukan, menjalankan, melaksanakan (to do or carry of a execute), (2) 
memenuhi atau melaksanakan kewajiban suatu niat atau nazar (to discharge of fulfil as vow), (3) melaksanakan atau menyempurnakan tanggung jawab (to execute or complete an understaking), (4) melakukan sesuatu yang diharapkan oleh seseorang atau mesin (to do what is expected of a person machine).

Dari beberapa definisi yang telah dikemukakan diatas, maka kesimpulan pengertian atau definisi kinerja atau performance adalah: hasil kerja yang dapat dicapai oleh sesorang atau sekelompok orang dalam suatu organisasi baik secara kuantitatif maupun kualitatif, sesuai dengan kewenangan dan tugas tanggung jawab masing-masing, dalam upaya mencapai tujuan organisasi bersangkutan secara legal, tidak melanggar hukum dan sesuai dengan moral maupun etika. Menurut Hasibuan (2015) mengemukakan bahwa aspek-aspek yang dinilai dalam penilaian kinerja mencakup sebelas aspek: 1) Kesetiaan, 2) Hasil kerja, 3) Kejujuran, 4) Kedisiplinan, 5) Kreativitas, 6) Kerjasama, 7) Kepemimpinan, 8) Kepribadian, 9) Prakarsa, 10) Kecakapan, dan 11) Tanggung jawab.

Keberhasilan kinerja sangat dipengaruhi oleh variabel lainnya sebagai variabel bebas (Independent variable) seperti pengembangan organisasi, kepemimpinan transformasional, budaya organisasi, dan motivasi (Edison;2016).

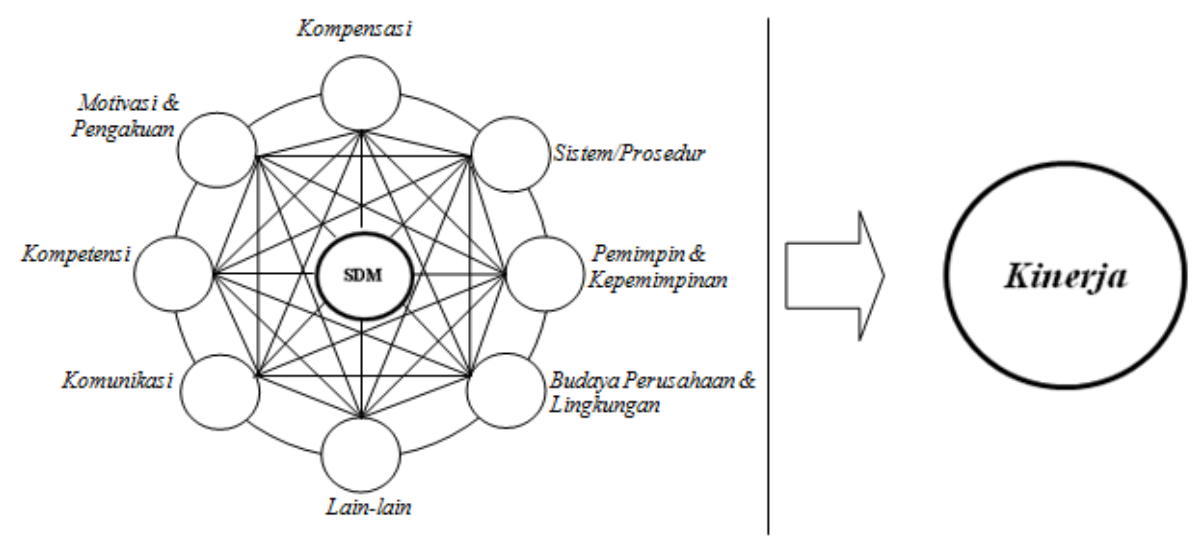

Gambar 1. Faktor yang Mempengaruhi Kinerja

Menurut Yukl (2001) pada setiap tahap dari proses transformasional, keberhasilan sebagian akan tergantung kepada sikap, nilai, dan keterampilan pemimpin tersebut. Para pemimpin transformasional yang efektif mempunyai atribut-atribut; Pemimpin transformasional melihat diri mereka sendiri sebagai agen-agen perubahan. Pemimpin transformasional fleksibel dan terbuka terhadap pelajaran dan pengalaman. Pemimpin transformasional mempunyai keterampilan kognitif, dan yakin kepada pemikiran yang berdisiplin dan kebutuhn akan analisis masalah yang hati-hati.

Umumnya, kepemimpinan transformasional berjalan dengan menggunakan Multifactor Leadership Questionare (MLQ) yang dikembangkan oleh (Bass dan Avolio, 1990). Menurutnya, 
kepemimpinan transformasional dapat dirinci ke dalam empat indikator, yakni: Karisma, Stimulasi intelektual (intellectual stimulation). Perhatian terindividualisasi (individualized consideration), Profesionalitas inspirasional (inspirational motivation). Berdasarkan uraian di atas dapat dikatakan bahwa kepemimpinan transformasional adalah sebuah proses di mana pemimpin dan pengikut saling menaikkan diri ke tingkat moralitas dan profesionalitas yang lebih tinggi dengan cara menyerukan cita-cita yang lebih tinggi dan nilai-nilai moral seperti kemerdekaan, keadilan, dan kemanusiaan, bukan berdasarkan atas emosi, seperti keserakahan, kecemburuan, atau kebencian.

Fakta menunjukkan bahwa kinerja SDM di lingkungan STIE belum sepenuhnya efektif. Hal ini bisa dilihat dari masih banyaknya STIE yang mempunyai kualitas lulusan yang kurang memuaskan. Untuk menjadi sebuah organisasi yang sukses, tantangan STIE ke depan adalah bagaimana meningkatkan dan menerapkan prinsip-prinsip profesionalitas dosen seperti yang tertuang dalam Undang-Undang Nomor 14 Tahun 2005 tentang Guru dan Dosen. Di antara faktor yang menyebabkan rendahnya kinerja dosen antara lain; Banyaknya pendidik yang tidak menekuni profesinya secara utuh, mereka bekerja di luar jam kerja untuk mendapatkan penghasilan tambahan demi kebutuhan sehari-hari. Budaya organisasi di lingkungan STIE belum tercipta budaya yang sifatnya memberikan dorongan agar para dosen lebih kreatif dan inovatif. Sehingga, penelitian ini bertujuan untuk mengetahui pengaruh pengembangan organisasi, kepemimpinan transformasional dan budaya organisasi terhadap komitmen dan kinerja dosen STIE di Provinsi Lampung.

\section{METODE PENELITIAN}

Berdasarkan tingkat eksplanasinya, penelitian ini bersifat deskriptif, asosiatif dan verifikatif. Penelitian deskriptif adalah penelitian yang bertujuan untuk memperoleh deskripsi tentang variabel yang diteliti yakni pengembangan organisasi/ PO $\left(\mathrm{X}_{1}\right)$, kepemimpinan transformasional / KT $\left(\mathrm{X}_{2}\right)$, budaya organisasi /BO $\left(\mathrm{X}_{3}\right)$ terhadap komiten dosen / KO (Y) dan Kinerja Dosen /KD (Z) Sekolah Tinggi Ilmu Ekonomi (STIE) di Provinsi Lampung. Jenis penelitian ini adalah causalitas (kausalitas) yaitu menguji hubungan sebab-akibat antara variabel-variabel sebab (exogent variables) dengan variabel akibat (endogent variabel).

\section{Populasi dan Sampel}

Dalam penelitian ini populasi yang akan diteliti adalah seluruh dosen tetap dan pejabat struktural yang telah memiliki Jenjang Jabatan Akademik (JA) di 7 (tujuh) PTS Sekolah Tinggi Ilmu Ekonomi (STIE) di Provinsi Lampung seluruhnya adalah 143 orang dosen. Sedangkan sampel dengan teknik non probabilty sampling ditemtukan sebanyan 70 orang dosen. 


\section{Definisi Operasional}

Dilihat dari segi variabelnya, penelitian ini terdiri atas 5 variabel yaitu pengembangan organisasi, kepemimpinan transformasional, budaya organisasi sebagai variabel eksogen, sedangkan variabel komitmen dosen sebagai variabel perantara endogen atau variabel intervening serta kinerja dosen sebagai variabel endogen.

\section{Teknik Pengumpulan Data}

Data dan informasi dikumpulkan langsung di tempat kejadian secara empirik (crossectional) dengan tujuan untuk mengetahui pendapat dari responden yang dijadikan sampel pada obyek yang diteliti. Subyek penelitian ini adalah individu, yaitu para dosen Sekolah Tinggi Ilmu Ekonomi (STIE) di Provinsi Lampung.

\section{Teknik Analisis Data}

Teknik ini menganalisis pola hubungan variabel exogenous terhadap variabel endogen yaitu variabel yang termasuk didalamnya mencakup semua variabel perantara dan tergantung. Kemudian menghitung besarnya pengaruh langsung (Direct effect) yang dapat dilihat dari koefisien jalur dari satu variabel ke variabel lainnya serta pengaruh tidak langsung (Indirect effect) yaitu urutan jalur melalui satu atau lebih variabel perantara.

$\mathrm{PO}\left(\mathrm{X}_{1}\right)$, kepemimpinan transformasional /KT $\left(\mathrm{X}_{2}\right)$, budaya organisasi /BO $\left(\mathrm{X}_{3}\right)$ terhadap komiten dosen /KO (Y) dan Kinerja Dosen /KD (Z) Sekolah Tinggi Ilmu Ekonomi (STIE) di Provinsi Lampung.

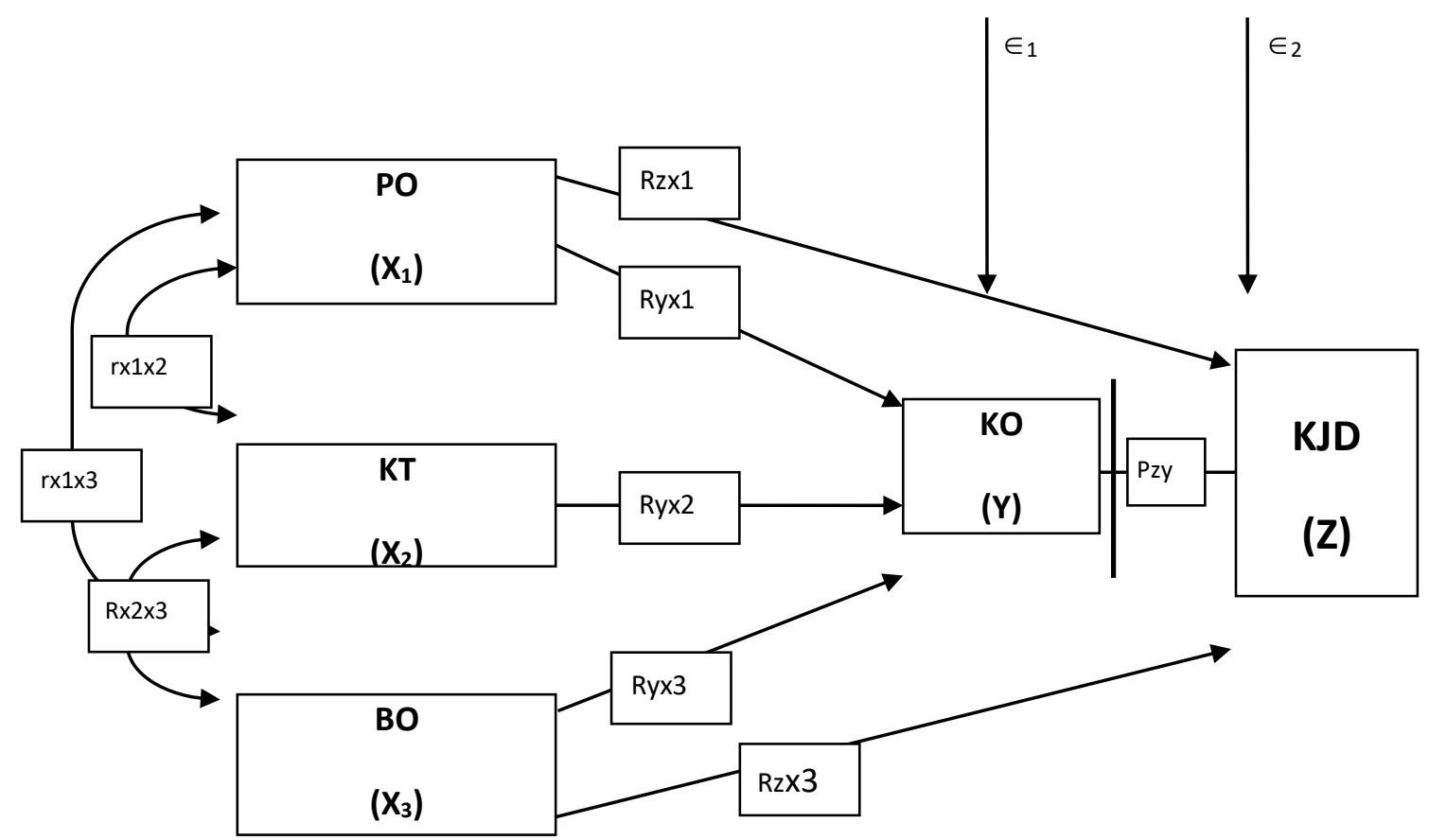

Gambar 2. Struktur Analisis Jalur (Path Analysis) 
Diagram jalur gambar 2 terdiri atas dua persamaan struktural di mana $X_{1}, X_{2}$, dan $X_{3}$ adalah variabel eksogen, sedangkan $\mathrm{Y}$ dan $\mathrm{Z}$ adalah variabel endogen. Persamaan strukturalnya dapat dilihat sebagai berikut:

$\mathrm{Y}=\mathrm{PYX}_{1}+\mathrm{PYX}_{2}+\mathrm{PYX}_{3}+\mathrm{C}_{1}($ Sebagai persamaan substruktur 1$)$

$\mathrm{Z}=\mathrm{PZ} \mathrm{X}_{1}+\mathrm{PZY}+\mathrm{PZX}_{3}+\mathrm{C}_{2}$ (Sebagai persamaan substruktur 2)

\section{HASIL DAN PEMBAHASAN}

\section{Pengaruh Variabel Eksogen Terhadap Variabel Perantara Endogen (intervening)}

Analisis Substruktur 1. Persamaan strukturalnya adalah $\mathrm{Y}=\mathrm{PYX}_{1}+\mathrm{PYX}_{2}+\mathrm{PYX}_{3}+\mathrm{C}_{1}$

Besarnya pengaruh langsung pengembangan organisasi/ PO $\left(\mathrm{X}_{1}\right)$, kepemimpinan transformasional / KT $\left(\mathrm{X}_{2}\right)$, budaya organisasi /BO $\left(\mathrm{X}_{3}\right)$ terhadap komitmen dosen/ KO (Y) Sekolah Tinggi Ilmu Ekonomi (STIE) di Provinsi Lampung serta besarnya korelasi dapat digambarkan dalam bentuk diagram sebagai berikut:

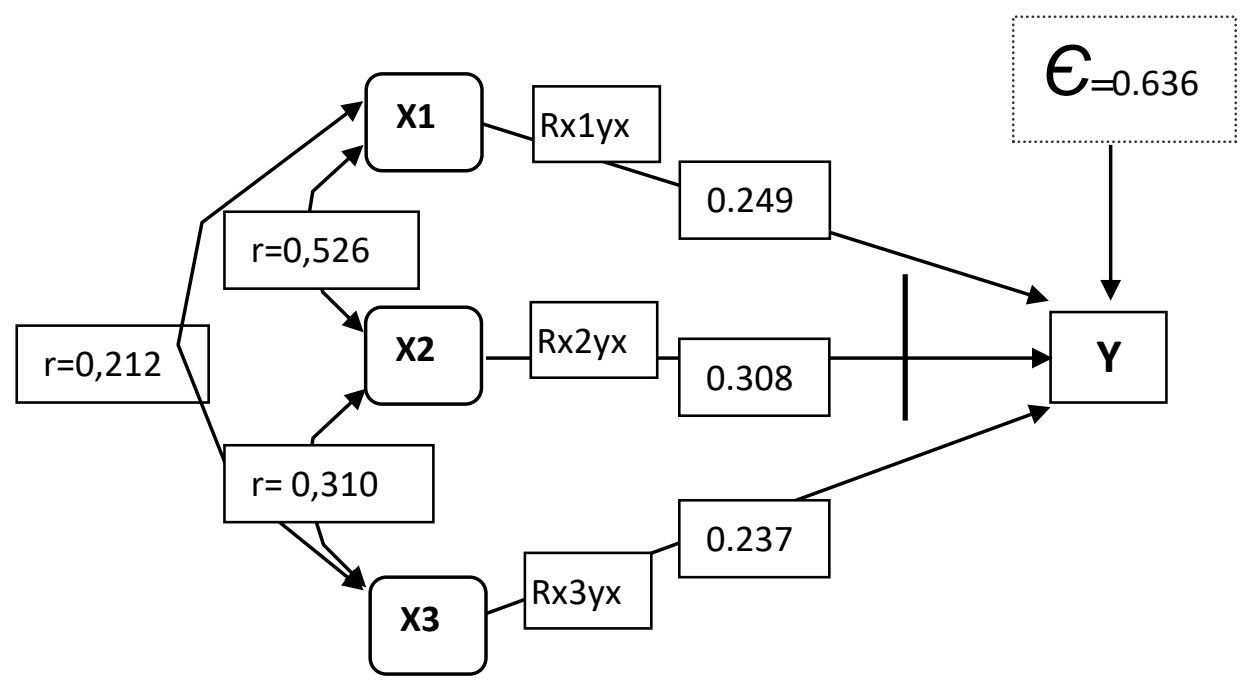

Gambar 3. Pengaruh Langsung Eksogen terhadap Intervening dan besar korelasi.

Dari gambar 3 terlihat terdapat pengaruh langsung variabel pengembangan organisasi, kepemimpinan transformasional, budaya organisasi terhadap komiten dosen Sekolah Tinggi Ilmu Ekonomi (STIE) di Provinsi Lampung baik secara parsial maupun simultan dan memiliki korelasi positif 


\section{Pengaruh variabel exogen terhadap variabel endogen}

\section{Analisis Substruktur 2 Persamaan strukturalnya adalah: $Z=P Z X_{1}+P Z Y+P Z X_{3}+G_{2}$.}

Besarnya pengaruh langsung pengembangan organisasi, kepemimpinan transformasional, budaya organisasi, komiten dosen terhadap kinerja dosen serta besarnya korelasi dapat digambarkan dalam bentuk diagram sebagai berikut:

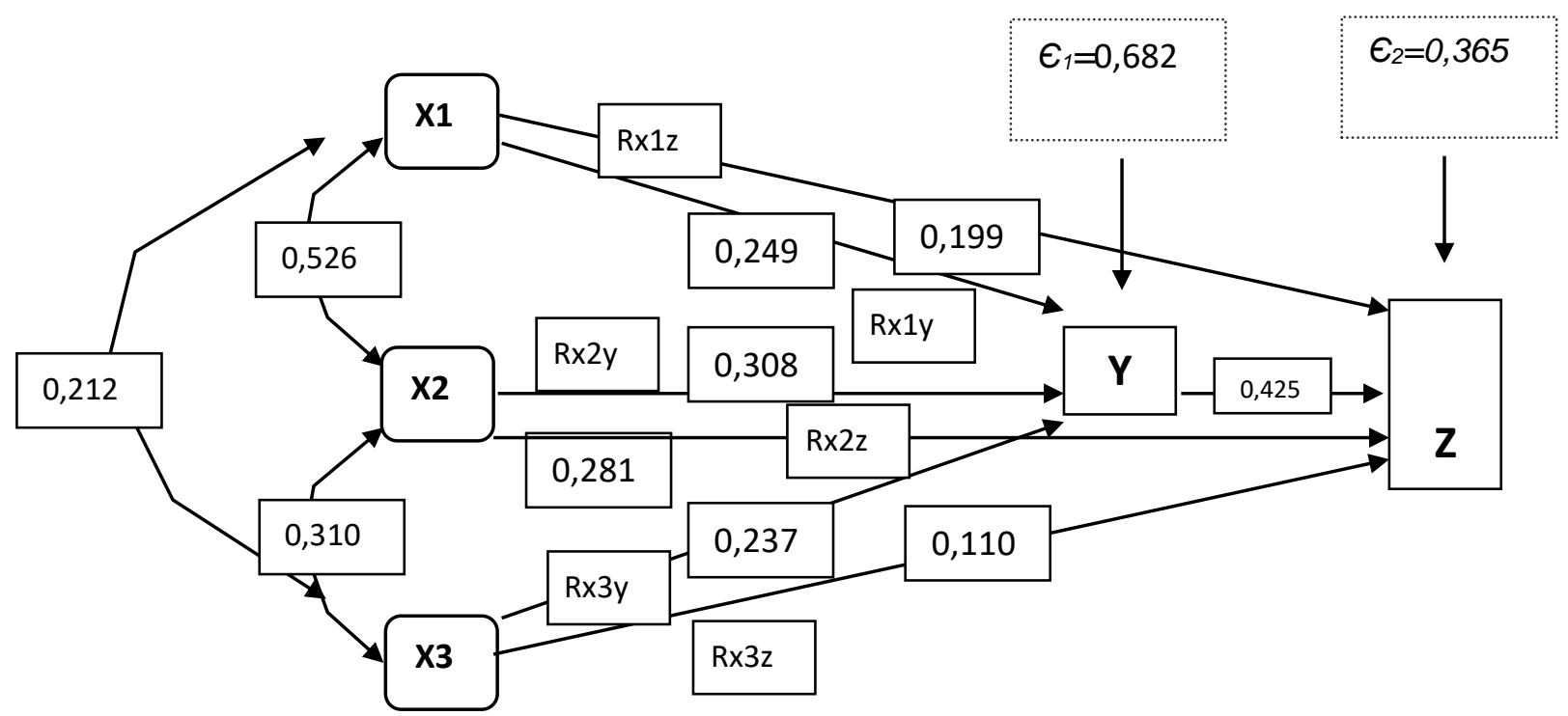

Gambar 4. Pengaruh variabel exogen terhadap variabel endogen

Dari gambar 4 terlihat terdapat pengaruh variabel pengembangan organisasi, kepemimpinan transformasional, budaya organisasi, terhadap kinerja dosen melalui variabel komitmen dosen Sekolah Tinggi Ilmu Ekonomi (STIE) di Provinsi Lampung baik secara parsial maupun simultan dan memiliki korelasi positif.

Secara lebih spesifik hasil temuan bahwa budaya organisasi memiliki pengaruh yang lebih besar terhadap komitmen maupun terhadap kinerja dosen. Meskipun budaya budaya organisasi memiliki hubungan dan pengaruh yang paling tinggi terhadap komitmen dan kinerja dosen STIE, namun perlu diperhatikan bahwa Pengembangan organisasi dan kepemimpinan transformasional juga memiliki hubungan dan pengaruh yang besar dalam meningkatkan komitmen dan kinerja dosen. Berdasarkan pengujian hipotesis dan pembahasan hasil penelitian diperoleh persamaan model Sub Struktur1 adalah $\hat{\mathrm{Y}}=0,249 \mathrm{X}_{1}+0,308 \mathrm{X}_{2}+0,237 \mathrm{X}_{3}+\epsilon_{1}$ Kemudian persamaan model Sub Struktur 2 adalah $\check{Z}=0,199 X_{1}+0,260 X_{2}+0,425 X_{3}+\epsilon_{2}$ artinya pengaruh variabel tertinggi adalah variabel budaya organisasi yakni 0,425 .

Budaya Organisasi khususnya terkait dengan pendidikan tinggi di STIE terdapat hubungan yang sangat erat. Pendidikan selalu berkaitan dengan manusia, sedang manusia selalu menjadi anggota 
masyarakat dan mendukung budaya tertentu. Konsep pendidikan mengangkat derajat manusia sebagai makhluk budaya yaitu makhluk yang mempunyai kemampuan untuk menciptakan nilai budaya dan fungsi budaya. Berdasarkan implikasi tersebut di atas maka dapat ditarik implikasi temuan teori dari penelitian ini yaitu: Optimalisasi pencapaian kinerja dosen STIE dapat dilakukan dengan cara mendorong komitmen kerja dosen melalui penyempurnaan pengembangan organisasi, kepemimpinan transformasional, dan membangun budaya organisasi yang komunikatif, kreatif, inovatif dan kompetitif.

\section{KESIMPULAN DAN SARAN}

Terdapat hubungan linier secara simultan antara terdapat pengaruh langsung variabel pengembangan organisasi, kepemimpinan transformasional, budaya organisasi terhadap kinerja dosen Sekolah Tinggi Ilmu Ekonomi (STIE) di Provinsi Lampung. Dengan demikian model regresi di atas sudah layak dan benar. Terdapat pengaruh variabel pengembangan organisasi, kepemimpinan transformasional, budaya organisasi dan komiten dosen terhadap kinerja dosen Sekolah Tinggi Ilmu Ekonomi (STIE) di Provinsi Lampung baik secara parsial maupun secara simultan.

\section{DAFTAR PUSTAKA}

Armstrong, Michael. Handbook of Performance Management.London: Kogan Page. 2009.

Davis Keith, New Strom, Jhon W., Perilaku Dalam Organisasi,Jilid I. Jakarta: Erlangga. 2002.

Dessler, Garry.Manajemen Sumber Daya Manusia. Jakarta: PT Ghalia Indonesia. 1999.

Drucker, Peter F.On High Performance Organization. Jakarta:PT Elex Media Komputindo, Gramedia. 2005.

Edison, Emron. Anwar, Yohni. Komariah, Imas.Manajemen Sumber Daya Manusia, Strategi Perubahan Dalam Rangka Meningkatkan Kinerja Pegawai Dan Organisasi. Bandung:CV. Alfabeta. 2016.

French, Bell, Zawacki, Organization Development and Transformation, Managing Effective Change: Mc Graw-Hill International. 2000.

Gomes, Faustino Cardoso.Manajemen Sumber Daya Manusia. Yogyakarta: Andy. 2003.

I Gusti Djestawa, Disertasi, Pengaruh Pengembangan Organisasi, Kepemimpinan, Pengembangan Karir Terhadap Kepuasan Kerja Dan Implikasinya Pada Kinerja Pegawai Puskesmas Kota Denpasar Propinsi Bali, Jakarta: Universitas Persada Indonesia 2009.

Istijanto. Aplikasi Praktis Riset Sumber Daya Manusia. Jakarta: Gramedia Pustaka Utama, 2005.

Jai B. P. Sinha, Culture and Organizational Behaviour. New Delhi, India: SAGE Publications India Pvt Ltd B1/I-1 Mohan Cooperative Industrial AreaMathura Road. www.sagepub. 2009. 
Jane Vella, Learning To Listen, Learning To Teach : The Power Of Dialogue In Educating Adults. San Francisco, CA: Josey-Bass, AWiley Company 989 Market Street. 2002.

Keyton, Joann, Communication and organizational culture: a key to understanding work experiences, California: Sage Publications, Inc. 2005.

Mahsusi, Disertasi, Pengaruh Kepemimpinan Transformasional Dan Budaya Organisasi Terhadap Profesionalitas Serta Implikasinya Pada Kinerja Guru Madrasah Aliyah Di DKI, Jakarta: Universitas Persada Indonesia, 2010

Moeheriono. Pengukuran Kinerja Berbasis Kompetensi. Jakarta: PT RajaGrafindo. 2012.

Mullins, Laurie J, Management \& Organisational Behaviour, Ninth Edition, England, Edinburgh GateHarlow Essex Cm20 2je. 2010.

Nawawi, Hadari. Manajemen Sumber Daya Manusia. Yogyakarta: Gadjah Mada University Press. 2013.

Prabu, Mangkunegara, A.A Anwar, Evaluasi Kinerja SDM. Bandung: PT Refika Aditama, 2014.

Robert, Golembiewsk T, Handbook of Organizational Behavior. New York: Headquarters Marcel Dekker, Inc.270 Madison Avenue. 2001.

Robert, Sherman R, Rodman B.Webb , Qualitative Research in Education: Focus and Methods. New York, USA: Routledge Falmer, 29 West 35th Street, published in the Taylor \& Francis e-Library. 2005.

Robins, P. Stephen, Organizational Behavior, $9^{\text {th }}$ Ed. New Jersey: Prentice Hall International, 2003.

Perilaku Organsiasi. Jakarta: PT. Indeks Gramedia. 2006.

Robins, P Stephen, dan Judge A. Timothy, Organizational Behavior, Edisi 12. Jakarta: Salemba Empat, 2008.

Sallis, Edward.Total Quality Management in Education. Jogjakarta: IRCiSoD. 2008.

Sarwono, Jonathan. Analisis Jalur Untuk Riset Bisnis dan SPSS. Yogyakarta: Andy. 2009.

Werther, William B, and Davis, Keith.Human Resources and Personnel Management. $5^{\text {th }}$ Edition, New York: McGraw-Hill Inc. 1996.

Wibowo, Budaya Organisasi, Sebuah Kebutuhan Untuk Meningkatkan Kinerja, Jangka Panjang. Jakarta: PT Raja Grafindo Perkasa. 2013.

---------, Manajemen Kinerja Edisi ke lima, Jakarta: PT Raja Grafindo Persada, 2016.

Widodo, Eko Suparno, Manajemen Pengembangan Sumber Daya Manusia. Yogyakarta: Pustaka Pelajar. 2015.

Wirawan.Budaya dan Iklim Organisasi Teori Aplikasi dan Penelitian. Jakarta: Salemba Empat. 2007. 
Yohni Anwar, Disertasi, Analisis pengaruh kepemimpinan, transformasional, kompetensi, kompensasi dan komitmen terhadap budaya organisasi serta implikasinya pada kinerja dosen. Cimahi: Universitas Pasundan, 2015.

Yopi Yulius, Disertasi, Pengaruh Gaya Kepemimpinan Dan Kompetensi Kerja Terhadap Motivasi Kerja, Serta Implikasinya Terhadap Kinerja Pegawai Operasional Pada Objek Wisata Taman Rekreasi Di Dki Jakarta, Jakarta: Universitas Persada Indonesia, 2008. 